\title{
Age-related differences in reproductive success support the selection hypothesis in a Mute Swan population
}

\author{
Radosław Włodarczyk $^{1}$ (D) $\cdot$ Piotr Minias ${ }^{1}$
}

Received: 3 October 2019 / Revised: 30 June 2020 / Accepted: 13 July 2020 / Published online: 23 July 2020

(c) The Author(s) 2020

\begin{abstract}
In many bird species, we observe age-related differences in reproductive success, which usually increases early in life and later decreases due to senescence. At the individual level, an early-life improvement in breeding performance may be associated with experience acquired during early reproductive events (experience hypothesis). At the population level, higher average reproductive success of older age cohorts can result from a disappearance of low-quality individuals from the population (selection hypothesis). Here, we tested these hypotheses in a wild population of the Mute Swan Cygnus olor from central Poland. In 1996-2016, we collected information on breeding success of 150 marked individuals ( 70 females and 80 males; 590 breeding attempts). At the population level, there was an initial increase in reproductive success (1-5 years), followed by a plateau (5-8 years), and then by a decrease in older age classes. Both within- and between-individual age variation contributed to the linear increase in reproductive success at the population level, but the latter effect was much more apparent. Short-term breeders ( $\leq 2$ breeding events) had significantly lower reproductive success than long-term breeders ( $\geq 3$ breeding events) during their first two breeding attempts, providing support for selection hypothesis and disappearance of low-quality phenotypes. After exclusion of short-term breeders, a positive age-related increase in reproductive success lost significance, suggesting that under-specific condition (rapid population growth and strong human disturbance) experience may have a limited effect on reproductive success in long-lived species with strong pair bonds, such as the Mute Swan.
\end{abstract}

Keywords Age $\cdot$ Mute Swan $\cdot$ Phenotype disappearance $\cdot$ Reproductive success $\cdot$ Selection hypothesis

\section{Zusammenfassung}

Altersbedingte Unterschiede im Reproduktionserfolg einer Höckerschwan-Population unterstützen die Selektionshypothese

Für viele Vogelarten stellen wir altersbedingte Unterschiede im Reproduktionserfolg fest, der normalerweise in der Jugend anwächst und später im Alter wieder nachlässt. Auf individueller Ebene ist eine Verbesserung der Brutleistung in der Jugend möglicherweise mit Erfahrungen aus frühen Fortpflanzungserlebnissen verbunden (Erfahrungshypothese). Auf Populationsebene könnte ein höherer Reproduktionserfolg älterer Altersgruppen aus dem Verschwinden von Individuen minderer Qualität resultieren (Selektionshypothese). Wir untersuchten beide Hypothesen an einer wildlebenden Höckerschwan-Population (Cygnus olor) in Zentralpolen. Von 1996 bis 2016 sammelten wir Informationen zum Bruterfolg von 150 markierten Einzeltieren (70 Weibchen und 80 Männchen; 590 Brutansätze). Auf Populationsebene gab es zunächst eine Zunahme des Bruterfolgs (1-5 Jahre), gefolgt von einem Plateau (5-8 Jahre) und dann einer Abnahme bei den älteren Jahrgängen. Die Altersschwankungen sowohl der einzelnen als auch zwischen den Tieren trugen zu einem linearen Anstieg des Reproduktionserfolgs auf der Populationsebene bei, wobei der Effekt der letzteren Gruppe aber der wesentlich größere

Communicated by O. Krüger.

Radosław Włodarczyk

radoslaw.wlodarczyk@biol.uni.lodz.pl

1 Department of Biodiversity Studies and Bioeducation, Faculty of Biology and Environmental Protection, University of Łódź, Banacha 1/3, 90-237 Łódź, Poland 
war. Kurzzeit-Brütende ( $\leq 2$ Brutansätze) hatten einen signifikant geringeren Bruterfolg als Langzeit-Brüter ( $\geq 3$ Brutansätze) während ihrer ersten zwei Brutversuche, was die Selektionshypothese und das Verschwinden von Phenotypen geringerer Qualität unterstützt. Lässt man die Kurzzeit-Brüter aus der Rechnung heraus, verliert der positive, altersbedingte Anstieg des Bruterfolgs an Bedeutung, was darauf hindeutet, dass unter bestimmten Bedingungen (rasches Wachsen der Population, starke Störungen durch Menschen) bei langlebigen Arten mit starker Paarbindung wie dem Höckerschwan Erfahrungen nur einen begrenzten Einfluss auf den Fortpflanzungserfolg haben könnten.

\section{Introduction}

In many bird species that reproduce during several seasons over their lifetime, age-related differences in reproductive success and survival have been demonstrated (e.g. Berman et al. 2009; Clutton-Brock 1988; Weimerskirch 1992; Wiebe and Martin 1994; Saino et al. 2002; Cichoń 2003; Rebke et al. 2010). In general, breeding success is expected to increase during early breeding attempts, stabilize at midage classes, and decline towards the end of life due to the senescence (Forslund and Pärt 1995).

Four hypotheses have been proposed to explain age-related variation in breeding success at the individual and population level: (1) the selection or differential mortality hypothesis, which assumes continuous disappearance of low-quality individuals from the population (Curio 1983; Forslund and Pärt 1995) (2) the recruitment hypothesis based on the progressive appearance of high-quality breeders, which delay their first breeding attempt, in the population (Forslund and Pärt 1995; Mauck et al. 2004) (3) the constraint or experience hypothesis suggesting that immature individuals are less effective during reproduction due to insufficient reproductive experience (Curio 1983; Wood et al. 2016); and (4) the effort or restraint hypothesis based on age-specific breeding investment (Stearns 1992; Forslund and Pärt 1995). Although these hypotheses are not mutually exclusive, they markedly differ in specific predictions on the mechanisms that drive the correlation between age and breeding success at the population and individual level (Martin 1995; Mauck et al. 2004).

The first two scenarios (selection and recruitment hypotheses) assume that variation in breeding success is primarily driven by population rather than within-individual changes in reproductive output. According to these hypotheses, individuals of low phenotypic quality may recruit in population, but they are also expected to disappear from the population relatively early (short-term breeders) because of reduced survival (disappearance of phenotypes). In contrast, individuals of higher quality may delay breeding, but they should remain in the breeding population for a longer time (long-term breeders) (Mauck et al. 2004; Steenhof and Heath 2009). Consequently, breeding success of early age cohorts is usually dominated by the contribution of lowquality individuals, while only high-quality individuals should be able to survive and continue breeding till intermediate or old age, resulting in a progressive age-related increase in the breeding success at the population level. On the other hand, the two remaining scenarios (experience and restraint hypotheses) assume that age-related variation in breeding success is primarily driven by within-individual processes. Specifically, the experience hypothesis assumes that reproductive success can be improved with age due to higher parental efficiency of older individuals, resulting from better competence in such activities as provision of better protection for the broods (against predators or unfavourable weather conditions in rainy or windy days) or higher food provisioning rate (Pyle et al. 2001; Limmer and Becker 2009). Also, experience gained during early breeding events can result in better breeding performance without a proportional increase in the costs of reproduction (Curio 1983). Finally, under the effort hypothesis, reproductive investment should increase in older individuals as residual reproductive value decreases with age. Thus, an increase in the success of consecutive breeding attempts of the same individuals would support predictions of the experience and restraint hypotheses (Newton and Rothery 1998).

Population studies of long-lived bird species can give a detailed insight into age-specific variation of life-history traits (e.g. Angelier et al. 2007; Mauck et al. 2004). Among different bird groups, swans and geese can be used as model species in life-history studies, due to their extended lifespan and high site/mate fidelity (Sedinger et al. 1995; Weiß et al. 2010). However, so far only few studies have addressed age-related differences in life-history traits in wildfowl (e.g. Rockwell et al. 1983; Scott 1988; Charmantier et al. 2006). In the case of the Mute Swan Cygnus olor, most of available information comes from a colonially breeding population from Abbotsbury Swannery, Dorset (McCleery et al. 2008; Auld et al. 2013). The aim of this paper was to analyse age-related variation in breeding performance of Mute Swans from a wild population in Central Poland. To test the hypotheses on age-related differences in breeding success, we collected long-term data on the reproductive output of 590 breeding attempts of 150 marked individuals.

\section{Methods}

The study was performed between 1996 and 2016 within an area of $8800 \mathrm{~km}^{2}$ in central Poland, Łódź province $\left(51^{\circ} 12^{\prime} \mathrm{N}\right.$, $\left.18^{\circ} 45^{\prime} \mathrm{E} ; 52^{\circ} 07^{\prime} \mathrm{N}, 20^{\circ} 04^{\prime} \mathrm{E}\right)$. The size of the local breeding 
population of Mute Swans was estimated at 70-100 pairs (Włodarczyk and Janiszewski 2007). Swans occupied different habitats, mainly artificial water bodies, such as fishponds, ponds used for recreation and dam reservoirs (Włodarczyk and Janiszewski 2007). The breeding population was stable with no major changes between years during the study period (Włodarczyk and Minias 2016). The majority of swans from our study population are migratory and they normally leave breeding territories in September-October, while they return to breed in January-March. Only a small proportion of pairs (ca. 6.5\%) occupy their breeding territories all year long, which is similar to other Mute Swan populations (Scott 1984). Each year, field observations started in March when all potential breeding territories were visited to find territorial pairs. We were able to detect the majority of pairs as the study area contains a limited number of suitable water bodies for swans and the birds do not show fear of human presence (Włodarczyk and Minias 2016). Each territory was visited four times during the breeding season, in April, May, June and August. During visits, we collected data on basic reproductive parameters, including laying date, clutch size, and the number of hatched and fledged cygnets. Moreover, we tried to detect all individuals that were marked in previous seasons and observed as breeders within the study area.

During the visits, unmarked breeding pairs were caught and ringed. Ringing activity of breeding birds was performed in May (incubating females) and August (both sexes with cygnets). Ringing effort was similar in each year (10-15 breeders ringed annually). Except for the direct marking of breeding pairs, we performed regular ringing of non-breeding individuals at traditional moulting sites within the study area, and in 1998-2016 we ringed 973 moulting birds. Ringing activity was also performed in winter (December-January), not only within the study area, but also in wintering flocks up to $50 \mathrm{~km}$ away from its boundaries ( $n=1040$ swans marked). The intensive ringing effort produced a relatively high proportion of marked individuals within our study population, and from year 2000 onwards the majority of new recruits within the study area consisted of marked birds.

Long-term observations of new recruits allowed us to gather information about life history of 150 marked individuals ( 70 females and 80 males) and their 590 breeding attempts. New recruits in the population were identified as: (1) marked floaters that were observed breeding for the first time, (2) unmarked birds that settled in territories occupied in previous year by ringed birds, or (3) unmarked birds that settled in a previously unoccupied territory. Although some cases from the latter two groups could be associated with breeding dispersal, our previous analysis of marked birds from the same population showed that breeding dispersal rate was low (recorded only in $21.5 \%$ of pairs) and short distance (average of $4.8 \mathrm{~km}$, often within the same fishpond complex) (Włodarczyk et al. 2013). Re-sighting data from the Polish Ringing Centre provided further support for low dispersal rate of swans breeding in Central Poland, as only one bird marked as breeder within our study area was observed breeding in another part of the country, despite the huge total number of re-sightings collected in 1996-2018 (ca. 9300). Consequently, we believe that it is safe to assume that the large majority of unmarked birds settling in new territories reflected recruitment of floaters into the population. These birds probably bred for the first time, but we could not determine their exact age. However, results from other populations with high percentages of marked juveniles showed that the age at the time of the first reproduction is not highly variable and the majority of swans initiate reproduction within 5 years from fledging (Perrins et al. 1994; Coleman et al. 2001; Wieloch et al. 2004). The end of reproductive activity of an individual was determined when death of a breeding bird was reported (7\% of individuals) or based on field observations. We assumed that birds that were not observed as breeders within our study area during three consecutive years could be claimed dead or non-breeding for the rest of their life. Our approach was based on field data as we did not collect any case of swans recommencing breeding after a 3 years' break. Although the exact age could not be determined for most of our birds (most recruits were not marked as juveniles), we were able to quantify reproductive age of all individuals, in terms of breeding years, and the lifetime number of reproductive episodes per individual. Due to low sample size $(n=35)$, reproductive episodes of birds with a reproductive age of more than 9 years were grouped into one category for the purpose of analyses.

We analysed differences in reproductive success during consecutive breeding attempts with general linear mixed models (GLMM), where the identity of individual was entered as a random factor to avoid pseudoreplication resulting from multiple measurements of the same birds breeding repeatedly within the study area. The effect of reproductive age was entered as a fixed factor. Following recommendations of Ruxton and Beauchamp (2008), we used contrast analysis to test how breeding success varied with reproductive age in our study population. Contrast analysis allows to test for a particular pattern of differences among the means. The contrasts are built using least squares means of the effect and contrast coefficients are normalized to make their sum zero (Lehman et al. 2013). A joint $F$ test for all contrasts is used to test for the linear or non-linear (quadratic) pattern of differences among means. First, we tested for age-related negative quadratic and positive linear trends in breeding success using the entire dataset. Due to the senescence-related reduction in the breeding success (as assessed from a significant negative quadratic trend, $P<0.001$, see results for details), we repeated fitting quadratic trends while successively excluding the oldest categories of reproductive age 
from the dataset. Maximal reproductive age at which the quadratic trend lost its significance was set as a threshold for senescence-related reduction in reproductive success and older age categories were excluded from the further analyses. Then, we used the contrast analysis to test for the positive trend of reproductive success with age (dataset with oldest age categories excluded).

We used three approaches to test for the individual competence (experience) versus phenotype disappearance (selection) hypothesis. First, we separated within- and betweenindividual effects of age on the reproductive success using within-group centering, where the centered value (representing a within-individual age effect) and the mean value of each individual (representing a between-individual age effect) were included in the same GLMM (van de Pol and Wright 2009). This model was fitted to data associated with a linear increase in reproductive success at the population level (1-8 first reproductive years, see results for details). We assumed a significant within-individual effect to be consistent with individual competence hypothesis, while a significant between-individual effect would provide support for the phenotype disappearance hypothesis. We also fitted a similar model with squared effects of both (within- and betweenindividual) age predictors (entire dataset, 1-17 reproductive years). We expected that the negative non-linear effect of age should be primarily apparent at the within-individual level, consistently with an individual decline in reproductive performance due to senescence.

Second, we compared reproductive success of short-term breeders that disappeared early from the population (after one or two breeding attempts) with reproductive success during the first two breeding attempts of individuals that stayed in the population for a longer time ( $\geq 3$ breeding attempts in total, henceforth referred to as long-term breeders). For this purpose, we used a GLMM with the breeding attempt (first versus second), breeder category (short-term versus long-term breeders) and an interaction between them included as fixed factors. We assumed that lower reproductive success of short-term breeders would be consistent with the phenotype disappearance hypothesis.

Third, we used contrast analysis incorporated in the GLMM to test for the positive linear trend in reproductive success of long-term breeders only (after exclusion of data for short-term breeders). We assumed that statistical significance of this trend would be consistent with the individual competence hypothesis. All GLMM models were fitted using the restricted maximum likelihood (REML) method. With this approach, denominator degrees of freedom are calculated using a Satterthwaite approximation, which can result in fractional degrees of freedom (Satterthwaite 1946). The identity of individual was entered as a random factor in each model. All GLMMs were implemented in JMP Pro
13 (SAS Institute Inc., Cary, NC, USA). All values were presented as means $\pm \mathrm{SE}$.

\section{Results}

A large proportion of birds within the study population were observed as breeders only during 1 or 2 seasons ( 0.48 of males and 0.45 of females). The average lifetime number of reproductive episodes was $3.87 \pm 0.34$ and $4.00 \pm 0.39$ for males and females, respectively, which did not constitute a significant difference $(t=0.23, d f=148, P=0.81)$. Only $4.0 \%$ of females and $4.6 \%$ of males bred for more than 10 years. The longest lifetime number of reproductive episodes was 17 years for females and 14 years for males (Fig. 1).

After controlling for the random effect of individual identity $(5.12 \pm 0.33$ and $0.75 \pm 0.25$ for residual and random variance), we found significant variation in reproductive success among different age classes in our study population of the Mute $\operatorname{Swan}\left(F_{9,516.1}=2.66, P=0.005\right.$; Fig. 2). This variation was better explained by the negative quadratic (contrast analysis: $F_{1,540.5}=17.95, P<0.001$ ) rather than positive linear trend that was non-significant (contrast analysis: $F_{1,556.9}=0.78, P=0.38$ ). This pattern likely reflected senescence-related reduction in reproductive success of the longest breeding individuals (breeding for more than 8 years; Fig. 2). After exclusion of this group, the quadratic trend in breeding success lost significance (contrast analysis: $F_{1,457.8}=0.29, P=0.59$ ), while the positive linear trend became highly significant (contrast analysis: $F_{1,525.6}=8.11, P=0.005$ ), indicating an increase in reproductive success with breeding age at the population level. This linear increase was mostly apparent during the first 5 years since the first reproduction (contrast analysis: $\left.F_{1,420.0}=8.89, P=0.003\right)$, when the mean reproductive success changed from $3.31 \pm 0.20$ (first reproduction event) to $4.39 \pm 0.36$ (fifth reproductive event) young fledged per pair at the population level (Fig. 2). Afterwards, there was a plateau from the fifth until the eighth reproductive event with no significant linear trend during this period (contrast analysis: $F_{1,96.3}=0.03, P=0.85$ ).

Separation of within- and between-individual effects of age indicated that the population increase in reproductive success (1-8 reproductive years) was apparent at both levels. We found that reproductive success was positively associated with within- and between-individual age variation, although the latter effects were much stronger in terms of statistical significance (Table 1). A non-linear model fitted to the entire dataset (1-17 reproductive years) provided evidence for a strong negative effect of squared within-individual age on reproductive 
Fig. 1 Lifetime number of breeding attempts in female (black bars) and male (white bars) Mute Swans from central Poland
Fig. 2 Reproductive success (the number of fledged offspring) during the successive breeding attempts (reproductive age) of Mute Swans (mean \pm SE are presented, number of cases in parentheses)
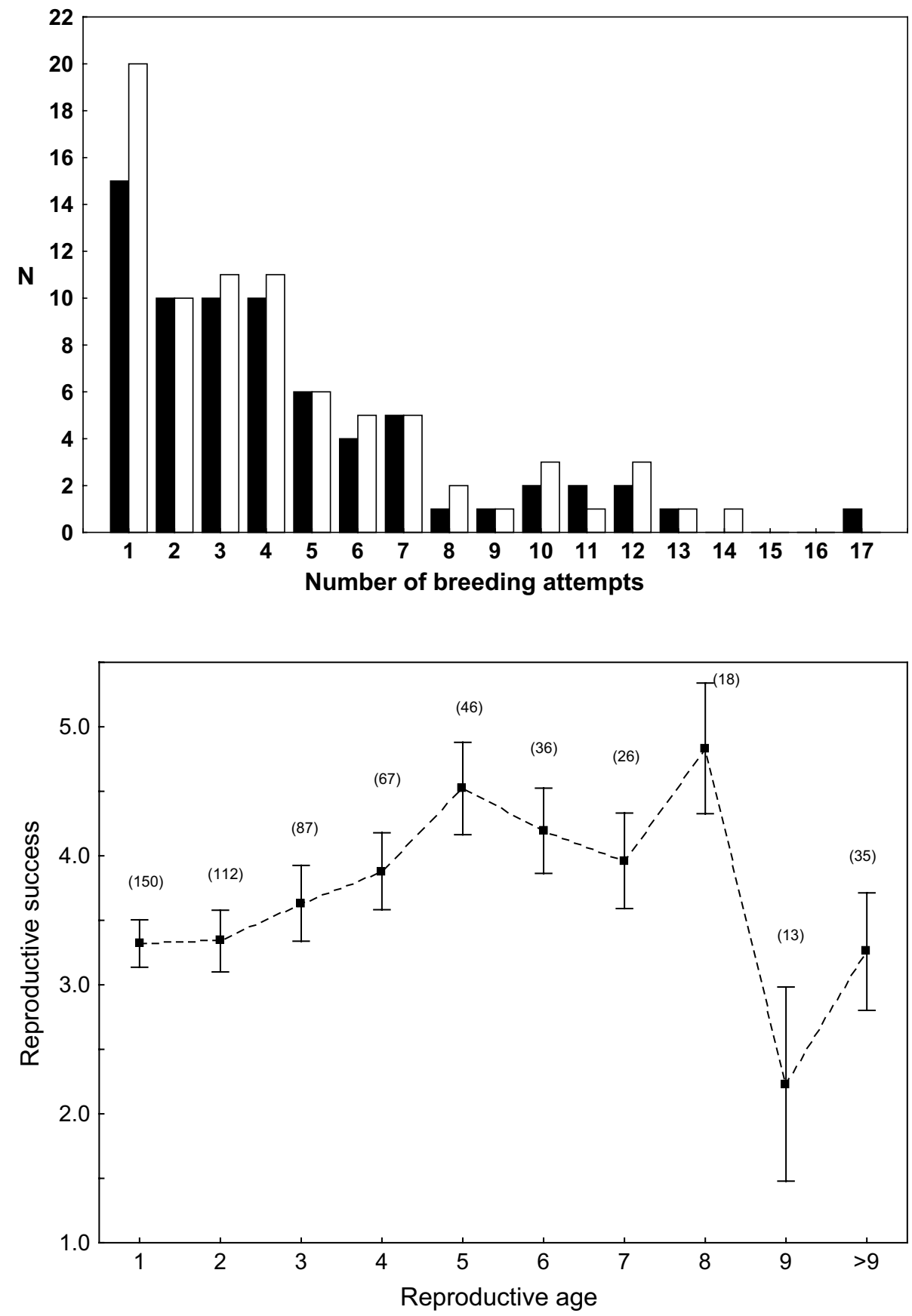

success (Table 1), being consistent with an individual decline in reproductive performance due to senescence.

We also tested whether reproductive success during the first two breeding attempts differed between individuals that disappeared early from the population (short-term breeders) and those that continued to breed for a longer time (long-term breeders). When controlling for the random effect of individual identity $(4.48 \pm 0.57$ and $1.04 \pm 0.50$ for residual and random variance), we found that short-term breeders had significantly lower reproductive success than long-term breeders during the first two breeding attempts $(2.75 \pm 0.45$ vs. $3.57 \pm 0.35$; $F_{1,175.1}=5.68, P=0.01$, Fig. 3). There was no difference in the reproductive success between the first and the second breeding attempt $\left(F_{1,162.5}=0.70, P=0.40\right)$ in neither short- or long-term breeders (interaction: $F_{1,162.5}=0.77$, $P=0.38$ ). After exclusion of short-term breeders from the entire dataset, we found that the positive linear trend of reproductive success with breeding age lost significance $\left(F_{1,448.6}=0.01, P=0.9\right)$. 
Table 1 The results of general mixed models showing withinand between-individual effects of age on reproductive success of Mute Swans

\begin{tabular}{llcrr}
\hline Model & Predictor & Estimate \pm SE & \multicolumn{1}{c}{$t$} & \multicolumn{1}{c}{$p$} \\
\hline Linear (1-8 years) & Intercept & $\mathbf{2 . 6 8} \pm \mathbf{0 . 2 7}$ & $\mathbf{1 0 . 0 8}$ & $<\mathbf{0 . 0 0 1}$ \\
& Within-individual age & $\mathbf{0 . 0 1 2} \pm \mathbf{0 . 0 5 7}$ & $\mathbf{2 . 0 2}$ & $\mathbf{0 . 0 4 4}$ \\
& Between-individual age & $\mathbf{0 . 2 9 8} \pm \mathbf{0 . 0 7 7}$ & $\mathbf{3 . 9 8}$ & $<\mathbf{0 . 0 0 1}$ \\
Non-linear (1-17 years) & Intercept & $\mathbf{7 . 6 8} \pm \mathbf{1 . 5 6}$ & $\mathbf{4 . 9 2}$ & $<\mathbf{0 . 0 0 1}$ \\
& Within-individual age & $\mathbf{0 . 9 8} \pm \mathbf{0 . 3 0}$ & $\mathbf{3 . 2 8}$ & $\mathbf{0 . 0 0 1}$ \\
& Within-individual age & $\mathbf{- 0 . 0 5 2} \pm \mathbf{0 . 0 1 5}$ & $\mathbf{3 . 4 9}$ & $<\mathbf{0 . 0 0 1}$ \\
& (squared) & & & \\
& Between-individual age & $0.46 \pm 0.27$ & 1.71 & 0.090 \\
& Between-individual age (squared) & $-0.020 \pm 0.032$ & 0.62 & 0.53 \\
\hline
\end{tabular}

Linear and non-linear models were fitted for different ranges of reproductive age. Random effect of individual identity was included in each model. Variance component estimates were [ $1-8$ years: $4.86 \pm 0.33$ (SE) and $0.80 \pm 0.26$ (SE) for residual and random variance; $1-17$ years: $5.09 \pm 0.33$ (SE) and $0.77 \pm 0.25$ (SE) for residual and random variance]. Significant predictors are marked in bold

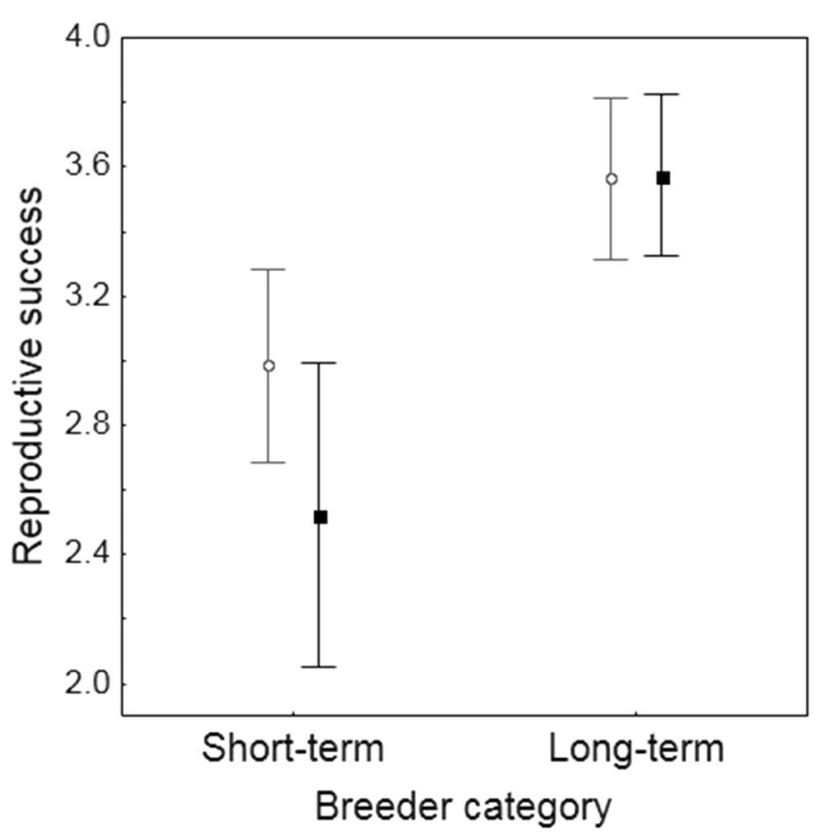

Fig. 3 Reproductive success during the first (open circles) and the second (filled squares) breeding attempt of short- and long-term breeders (mean \pm SE are presented)

\section{Discussion}

In this study, we observed a negative quadratic relationship between age and reproductive success in a Mute Swan population from central Poland. At the population level, breeding success increased during early breeding attempts ( $1-5$ years), then reached a plateau (5-8 years), and finally decreased in the oldest ( $>8$ years) age classes. Both within- and between-individual age variation contributed to the positive linear trend in reproductive success at the population level, although the latter effect (between individuals) was much more apparent, consistently with the selection hypothesis. We also found that the initial increase in average breeding success within the population was a result of disappearance of poor quality phenotypes, providing further support for selection hypothesis. In contrast, our results provided little support for the experience hypothesis, as the within-individual effect of age variation was weak and we found no significant age-related increase in breeding success of long-term breeders (high-quality phenotypes).

Theoretical models suggest that experience can strongly improve breeding performance, especially in long-lived species with strong pair bonds (Forslund and Pärt 1995). A study of semi-natural population of Mute Swans from Abbotsbury Swannery showed a stable improvement in breeding performance up to the age of 6-7 years (McCleery et al. 2008). The authors suggested that these differences in fledging success could be best explained by the experience gained in the successive breeding attempts (McCleery et al. 2008). Experience-related increase in breeding success was also observed in other swan species (Scott 1988; Wood et al. 2016) and a wide range of other non-passerine birds e.g. American Kestrel Falco sparverius, Cassin's Auklet Ptychoramphus aleuticus and Leach's Storm Petrel Oceanodroma leucorhoa (Pyle et al. 2001; Steenhof and Heath 2009; Mauck et al. 2004).

Field studies on wildfowl populations give indirect support for an improvement in breeding performance related to individual experience. For example, pair bonds in the Bewick's Swan Cygnus columbianus are very strong with marginal divorce rate (Rees et al. 1996) and a strong correlation between pair bond duration and the number of cygnets observed at wintering grounds with their parents (Scott 1988). Pair bond formation in the Mute Swan can last up to two years and birds are thought to choose future mates based on their age (experience) rather than morphology or body condition (Perrins and McCleery 1997). In addition, there is a strict division of parental duties between sexes, where females provide direct care to the offspring, while 
males guard the family and territory borders (Wieloch et al. 2004). Taking all this into account, it may be expected that breeding experience is likely to be an important determinant of reproductive output in swans.

However, here we found little evidence for an age-related improvement in breeding performance of long-term breeders. Although there was a weak, but significant, within-individual increase in reproductive success with age in Mute Swans from our study population, we found that betweenindividual effects were much stronger and that a linear increase in reproductive success at the population level was primarily driven by low reproductive performance of short-term breeders, which disappeared from the population after one or two breeding attempts. We suggest that this pattern can be possibly explained by a limited capacity of Mute Swans from our population to assess territory quality. In general, the process of territory choice should be based on individual experience, as birds use their previous knowledge to assess different (biotic an abiotic) components of territory quality (Storch and Frynta 2000). Individuals try to maximize their breeding success by choosing the best available territory, but the occurrence of random and unpredictable events during the breeding season can make selection of appropriate territories difficult. In our earlier research, we found no association between territory occupancy and reproductive output (hatching and fledging success) or adult body condition in our study swan population (Włodarczyk and Minias 2016). This means, that some pairs were likely to breed successively in poor quality territories, despite repeated breeding failures, which were often caused by unpredictable human disturbance, such as drainage of fish ponds before the conclusion of breeding activities (Włodarczyk and Minias 2016). An exposure to these unpredictable events may possibly explain a small role of breeding experience in shaping reproductive success of swans from our study population.

Our analysis showed that the positive age-related trend in breeding success at the population level was primarily caused by the initial contribution of low-quality individuals (short-term breeders). It means that selection can be identified as the major factor that produces variation in breeding performance between different age cohorts. Competition for vacant territories is strong in the Mute Swan following the rapid growth of European population size during the last century (Wieloch et al. 2004). Under such conditions, initial breeding attempts may be crucial for lifetime reproductive performance. Our data indicated that birds which succeeded in acquiring and maintaining a territory for the first two years had a relatively high probability of breeding for a longer time, which is consistent with studies on other long-lived species (Mauck et al. 2004). Because of selection leading to the disappearance of poor phenotypes, the proportion of high-quality individuals should gradually increase in the population and, simultaneously, average breeding success of individuals should also increase in older age cohorts (until senescence). So far, the selection hypothesis was found to best explain age-related changes in breeding performance in many other wild bird systems, including penguins, gulls and birds of prey (Johannesen et al. 2003; Cam and Monnat 2000; Espie et al. 2000).

We also provided evidence for a marked reduction in breeding success in the oldest age classes of the Mute Swan, resulting in a significant negative quadratic pattern of breeding success at the population level. This reduction in reproductive success was best explained by a within-individual effect of age, consistent with senescence mechanisms. A significant increase in breeding success during the first few breeding attempts is a well-known phenomenon in seabirds (Berman et al. 2009; Pyle et al. 2001), birds of prey (Steenhof and Heath 2009; Zabala and Zuberogoitia 2015), and wildfowl (Raveling 1981; Baillie and Milne 1982; Rockwell et al. 1983), but a senescence-related reduction in breeding performance was also recorded in a wide range of avian taxa, e.g. in the Sparrowhawk Accipiter nisus (Newton and Rothery 1998), Great Skua Stercorarius skua (Hamer and Furness 1991), Tree Swallow Tachycineta bicolor (Robertson and Rendell 2001), and Hawaiian Goose Branta sandvicensis (Woog 2002). A decrease in fertility of old individuals is often explained as a result of the cumulative effect of lateacting deleterious mutations or/and active selection of alleles with positive effects early in life, but negative later on (Rose 1991). The deleterious effect of mutations should reduce competitive ability of old birds, impacting their foraging efficiency, territory defence, brood protection or predator avoidance. Case observations of Mute Swan behaviour seem to support limited reproductive abilities of old individuals, as old pairs are often observed to hold their previous territories, but fail to initiate breeding (Coleman et al. 2001).

Finally, the results indicate that a large proportion of our Mute Swan breeding population consists of opportunistic breeders that are able to establish and occupy breeding territories for a short period of time. High turnover of breeders may seem surprising when we consider high longevity (up to 20 years) and long duration of pair bonds in the Mute Swan (Rees et al. 1996). However, a short average length of the lifetime reproductive period was also observed in a long-term study of sedentary Mute Swan population from central England (Coleman et al. 2001). In England, 49\% of males and $48 \%$ of females were observed breeding for no more than two seasons, which was similar to our estimate from central Poland (48\% and $45 \%$ of males and females, respectively).

High turnover of breeding birds can be explained by high annual mortality rate or/and strong intraspecific competition for territories. In the sedentary population from central England the annual mortality rate was relatively high (24-32\% 
in different age classes) with no major changes throughout the bird's life (Coleman et al. 2001). Although we lack any quantitative information on swan mortality in our study population, it seems likely that it may be even higher due to the migratory habit of birds, which travel several hundred kilometres from breeding to wintering grounds (Wieloch et al. 2004). In general, the migration period is associated with elevated mortality (Newton 2008) and the same pattern is expected in the Mute Swan, which is generally a poor flier and often suffers from collisions with buildings or electric lines (Brown et al. 1992; Collins 2002).

Also, the number of non-breeding birds clearly outnumbers the number of breeding individuals in many Mute Swan populations, which may lead to strong competition for suitable territories (Jenkins et al. 1976; Włodarczyk and Janiszewski 2007; Wood et al. 2013). Mute Swans are often highly aggressive during the breeding season and severe fights between competing individuals are frequently observed within territories (Birkhead and Perrins 1986). Under such circumstances, only individuals of high quality and sufficient competitive ability are able to occupy a territory continuously for many years. At the same time, natural selection is thought to be density-dependent, as individual probability of survival diminishes with increased intra-specific competition (Roughgarden 1971), which may reinforce the leading role of selection in shaping age-related patterns in reproductive success of Mute Swans.

In conclusion, our study provides empirical support for the selection hypothesis explaining age-related differences in breeding performance of Mute Swans at the population level. The results also suggest that even in long-lived species with strong pair ponds, under the conditions of rapid population growth, strong-intraspecific competition and human-related disturbance, breeding experience may have little effect on bird reproductive performance. We are convinced that our study adds to the understanding of mechanisms responsible for age-specific variation in reproduction that has been observed in many wild avian populations.

Acknowledgements We thank Tomasz Janiszewski, Tomasz Iciek, Adam Kaliński, and members of the Student's Ornithological Section University of Łódź who helped during fieldwork. We thank two anonymous reviewers for constructive comments on the earlier draft of the manuscript. Ringing of birds was performed with the approval of Polish Bird Ringing Centre, Museum and Institute of Zoology, Polish Academy of Sciences (Ringing licence: DLP-VIII-6713-21/29762/14/RN).

Open Access This article is licensed under a Creative Commons Attribution 4.0 International License, which permits use, sharing, adaptation, distribution and reproduction in any medium or format, as long as you give appropriate credit to the original author(s) and the source, provide a link to the Creative Commons licence, and indicate if changes were made. The images or other third party material in this article are included in the article's Creative Commons licence, unless indicated otherwise in a credit line to the material. If material is not included in the article's Creative Commons licence and your intended use is not permitted by statutory regulation or exceeds the permitted use, you will need to obtain permission directly from the copyright holder. To view a copy of this licence, visit http://creativecommons.org/licenses/by/4.0/.

\section{References}

Angelier F, Weimerskirch H, Dano S, Chastel O (2007) Age, experience and reproductive performance in a long-lived bird: a hormonal perspective. Behav Ecol Sociobiol 61:611-621

Auld JR, Perrins Ch, Charmantier A (2013) Who wears the pants in a mute swan pair? Deciphering the effects of male and female age and identity on breeding success. J Anim Ecol 82:826-835

Baillie SR, Milne H (1982) The influence of female age on breeding in the Eider Somateria mollissima. Bird Study 29:55-66

Berman M, Gaillard J-M, Weimerskirch H (2009) Contrasted patterns of age-specific reproduction in long-lived seabirds. Proc R Soc B 276:375-382

Birkhead M, Perrins CM (1986) The mute swan. Croom Helm, London

Brown MJ, Linton E, Rees EC (1992) Causes of mortality among wild swans in Britain. Wildfowl 43:70-79

Cam E, Monnat J-Y (2000) Stratification based on reproductive state reveals contrasting patterns of age-related variation in demographic parameters in the kittiwake. Oikos 90:560-574

Charmantier A, Perrins CH, McCleery RH, Sheldon BC (2006) Agedependent genetic variance in a life-history trait in the mute swan. Proc R Soc B 273:225-232

Cichoń M (2003) Does prior breeding experience improve reproductive success in collared flycatcher females? Oecologia 134:78-81

Clutton-Brock TH (1988) Reproductive Success. In: Clutton-Brock $\mathrm{TH}$ (ed) Reproductive success: studies of individual variation in contrasting breeding systems. University of Chicago Press, Chicago, pp 472-485

Coleman AE, Coleman JT, Coleman PA, Minton CDT (2001) A 39 year study of a Mute Swan Cygnus olor population in the English Midlands. Ardea 89:113-121

Collins R (2002) Sex differences in the movements and mortality of Mute Swans. In: Rees EC, Earnst S L, Coulson J (eds). Proceedings of the fourth international swan symposium; 2001. Waterbirds 25, Spec. Pub. 1:157-161

Curio E (1983) Why do young birds reproduce less well? Ibis 125:400-404

Espie RHM, Oliphant LW, James PC, Warkentin IG, Lieske DJ (2000) Age-dependent breeding performance in merlins (Falco columbarius). Ecology 81:3404-3415

Forslund P, Pärt T (1995) Age and reproduction in birds-hypotheses and tests. Trends Ecol Evol 10:374-378

Hamer KC, Furness RW (1991) Age-specific breeding performance and reproductive effort in Great Skuas Catharacta skua. J Anim Ecol 60:693-704

Jenkins D, Newton I, Brown C (1976) Structure and dynamics of a mute swan population. Wildfowl 27:77-82

Johannesen E, Houston D, Russell J (2003) Increased survival and breeding performance of double breeders in little penguins Eudyptula minor, New Zealand: evidence for individual bird quality? J Avian Biol 34:198-210

Lehman A, O'Rourke N, Hatcher L, Stepanski EJ (2013) JMP ${ }^{\circledR}$ for basic univariate and multivariate statistics: methods for researchers and social scientists, 2nd edn. SAS Institute Inc., Cary

Limmer B, Becker PH (2009) Improvement in chick provisioning with parental experience in a seabird. Anim Behav 77:1095-1101

Martin K (1995) Patterns and mechanisms for age-dependent reproduction and survival in birds. Am Zool 35:340-348 
Mauck RA, Huntington CE, Grubb TC (2004) Age-specific reproductive success: evidence for the selection hypothesis. Evolution 58:880-885

McCleery RH, Perrins CM, Sheldon BC, Charmantier A (2008) Agespecific reproduction in a long-lived species: the combined effects of senescence and individual quality. Proc R Soc B 275:963-970

Newton I (2008) The migration ecology of birds. Academic Press, London

Newton I, Rothery P (1998) Age-related trends in the breeding success of individual female Sparrowhawks Accipiter nisus. Ardea $86: 21-31$

Perrins CM, McCleery RH (1997) Pairing behaviour in a colony of mute swans Cygnus olor. Wildfowl 47:31-41

Perrins CM, McCleery RH, Ogilvie MA (1994) A study of the breeding Mute Swans Cygnus olor at Abbotsbury. Wildfowl 45:1-14

Pyle P, Sydeman WJ, Hester M (2001) Effect of age, breeding experience, mate fidelity and site fidelity on breeding performance in a declining population of Cassin's auklets. J Anim Ecol 70:1088-1097

Raveling DG (1981) Survival, experience, and age in relation to breeding success of Canada Geese. J Wildlife Manage 45:817-829

Rebke M, Coulson T, Becker PH, Vaupel JW (2010) Reproductive improvement and senescence in along-lived bird. Proc Natl Acad Sci USA 107:7841-7846

Rees EC, Lievesley P, Pettifor RA, Perrins C (1996) Mate fidelity in swans: an interspecific comparison. In: Black J (ed) Partnerships in birds: the study of monogamy. Oxford University Press, Oxford, pp 118-138

Robertson RJ, Rendell WB (2001) A long-term study of reproductive performance in tree swallows: the influence of age and senescence on output. J Anim Ecol 70:1014-1031

Rockwell RF, Findlay CS, Cooke F (1983) Life history studies of the lesser snow goose (Anser caerulescens caerulescens). Oecologia $56: 318-322$

Rose MR (1991) Evolutionary biology of ageing. Oxford Univ. Press, New York

Roughgarden J (1971) Density-dependent natural selection. Ecology $52: 453-468$

Ruxton GD, Beauchamp G (2008) Time for some a priori thinking about post hoc testing. Behav Ecol 19:690-693

Saino N, Ambrosini R, Martinnelli R, Møller AP (2002) Mate fidelity, senescence in breeding performance and reproductive trade-offs in the barn swallow. J Anim Ecol 71:309-319

Satterthwaite FE (1946) An approximation distribution of estimates of variance components. Biomet Bull 2:110-114

Scott DK (1984) Winter territoriality of mute swans Cygnus olor. Ibis 126:168-176

Scott DK (1988) Reproductive success in Bewick's Swans. In: CluttonBrock TH (ed) Reproductive success: studies of individual variation in contrasting breeding systems. University of Chicago Press, Chicago, pp 220-236

Sedinger JS, Flint PL, Lindberg MS (1995) Environmental Influence on Life-History Traits: growth, Survival, and Fecundity in Black Brant (Branta bernicla). Ecology 76:2404-2414
Stearns SC (1992) The evolution of life histories. Oxford University Press, New York

Steenhof K, Heath JA (2009) American Kestrel reproduction: evidence for the selection hypothesis and the role of dispersal. Ibis 151:493-501

Storch D, Frynta D (2000) Evolution of habitat selection: stochastic acquisition of cognitive clues? Evol Ecol 13:591-600

van de Pol M, Wright J (2009) A simple method for distinguishing within- versus between-subject effects using mixed models. Anim Behav 77:753-758

Weimerskirch H (1992) Reproductive effort in long-lived birds: agespecific patterns of condition, reproduction and survival in the wandering albatross. Oikos 64:464-473

Weiß BM, Kotrschal K, Möstl E, Hirschenhauser K (2010) Social and life-history correlates of hormonal partner compatibility in greylag geese (Anser anser). Behav Ecol 21:138-143

Wiebe KL, Martin K (1994) Growing old in the cold: environment, age and reproduction in two ptarmigan species. J Ornithol 135:385

Wieloch M, Włodarczyk R, Czapulak A (2004) The mute swan Cygnus olor. BWP Update 6:1-48

Włodarczyk R, Janiszewski T (2007) Abundance and distribution of the mute swan Cygnus olor in the Łódź region. Notatki Ornitologiczne 48:82-91 (In Polish with English summary)

Włodarczyk R, Minias P (2016) Non-adaptive territory selection by a bird with exceptionally long parental care. PeerJ 4:e1852

Włodarczyk R, Wieloch M, Czyż S, Dolata P, Minias P (2013) Natal and breeding dispersal in Mute Swans Cygnus olor: influence of sex, mate switching and reproductive success. Acta Ornithol 48:237-244

Wood KA, Stillman RA, Coombs T, McDonald C, Daunt F, O'Hare MT (2013) The role of season and social grouping on habitat use by mute swans (Cygnus olor) in a lowland river catchment. Bird Study 60:229-237

Wood KA, Newth JL, Hilton GM, Nolet BA, Rees EC (2016) Interannual variability and long-term trends in breeding success in a declining population of migratory swans. J Avian Biol 47:597-609

Woog F (2002) Reproductive success and pairing in Hawaiian Geese (Branta sandvicensis) in relation to age and body size. J Ornithol 143:43-50

Zabala J, Zuberogoitia I (2015) Breeding performance and survival in the peregrine falcon Falco peregrinus support an age-related competence improvement hypothesis mediated via an age threshold. J Avian Biol 45:141-150

Publisher's Note Springer Nature remains neutral with regard to jurisdictional claims in published maps and institutional affiliations. 